\title{
Annual trends in catchability and fish stock assessments*
}

\author{
PAUL MARCHAL ${ }^{1}$, CLARA ULRICH ${ }^{2}$, KNUT KORSBREKKE ${ }^{3}$, MARTIN PASTOORS $^{4}$ \\ and BRIAN RACKHAM ${ }^{5}$ \\ IIFREMER, 150, Quai Gambetta - BP 699, 62321 Boulogne sur mer, France. E-mail: paul.marchal@ifremer.fr \\ ${ }^{2}$ DIFRES, Charlottenlund Slot, DK 2920 Charlottenlund, Denmark. \\ ${ }^{3}$ IMR, P.O. Box 1870, N 5024 Bergen, Norway. \\ ${ }^{4}$ RIVO-DLO, P.O. Box 68, NL-1970 AB IJmuiden, The Netherlands. \\ ${ }^{5}$ CEFAS, Lowestoft Laboratory, Pakefield Road, Lowestoft, Suffolk NR33 0HT, UK.
}

\begin{abstract}
SUMMARY: A key assumption of many fish stock assessment models is that catchability is constant over time. We assume here that trends in catchability may occur through fishing power creeping. The tuning fleets, which are prone to fishing power development, may be identified using the "Hybrid" method. A range of catchability trends, including values derived from the "Hybrid" method, is then implemented to standardise the fishing effort of some tuning fleets used in the stock assessments performed by XSA (eXtended Survivors Analysis). Stocks being assessed are the North Sea cod, saithe, plaice and sole. The performances of the new and traditional XSA assessments are compared using criteria based on the precision of catchability estimates, stationarity of Log-catchability residuals and retrospective patterns relative to fishing mortality, spawning stock biomass and recruitment estimates. The performances of the North Sea cod, plaice and sole assessments could be enhanced by accounting for an overall annual increase in the catchability of some of the tuning fleets. No significant trends could be detected in the catchability of the tuning fleets relative to the assessment of the North Sea saithe. By contrast with the traditional assessment, the spawning biomass of cod is expected not to have increased between 1997 and 1998 , while the fishing mortality of sole is expected to have increased over the same period.
\end{abstract}

Key words: hybrid method, extended survivors analysis, fish stock assessment, catchability, fishing power, North Sea, trends, retrospective pattern.

\section{INTRODUCTION}

The catchability coefficient may be defined as the proportion of a fish population caught by one unit of fishing effort. Catchability $(q)$ is hence represented by the ratio between catch rates $(\mathrm{C} / \mathrm{E})$ and stock abundance $(\mathrm{N})$ :

$$
q=\left(\frac{C}{E}\right)\left(\frac{1}{N}\right)
$$

\footnotetext{
*Received August 24, 2000. Accepted January 28, 2002.
}

or equivalently by the ratio between fishing mortality (F) and fishing effort:

$$
\mathrm{q}=\frac{\mathrm{F}}{\mathrm{E}}
$$

The catchability coefficient has repeatedly been reported as an important source of uncertainty inherent to stock assessment models requiring fishing effort as input data (Cook and Armstrong, 1985; Pope and Shepherd, 1985; Megrey, 1989; ArreguinSanchez, 1996). Evidence is accumulating that the catchability of commercial fisheries is prone to non- 
random variations over time (Atran and Loesch, 1995; Pascoe and Robinson, 1996) and a number of formulations have been suggested to describe these trends. These formulations relate catchability variations to the distribution of the fish population relative to: (i) the distribution of fishing (or survey) effort (Crecco and Overholtz 1990; Swain et al., 1994); (ii) the effectiveness of the vessels in finding fish (fishing power) (Gascuel et al., 1993; Millischer et al., 1999); and (iii) having found fish, actually catching them (selectivity) (Arreguin-Sanchez and Pitcher, 1999). However, the lack of data relevant to catchability dynamics has hampered the inclusion of catchability models in stock assessment procedures (Megrey, 1989). Some stock assessment models allow for the direct estimation of annual catchabilities (e.g. Fournier and Archibald, 1982) or systematic trends in catchability (e.g. the "Hybrid method"; Pope and Shepherd, 1985) from catch and effort data. However, the estimates derived from the algorithm developed by Fournier and Archibald are prone to instability, as a result of over-parameterisation (Megrey, 1989), while fitting a time trend in catchability, using the "Hybrid" method, increases the sensitivity of the fishing mortality (F) estimates to the choice of the terminal $\mathrm{F}$ value (Pope and Shepherd, 1985). On the other hand, other stock assessment procedures ignore time dynamics in catchability (e.g. Paloheimo, 1980; Deriso et al., 1985). The XSA (eXtended Survivors Analysis) (Shepherd, 1999) incorporates some mechanisms of density-dependent catchability, but does not account for trends related to fishing power development. ICES stock assessments are frequently carried out using XSA. In these assessments, the possible effects of changes in catchability are alleviated by reducing the length of the time series of catch per unit effort (i.e. the "tuning window") used in the calibration equations (ICES, 2000). However, this approach is subject to criticisms, since the size of the tuning window is generally chosen arbitrarily and this procedure also means throwing away potentially useful information.

Results from past experiences and numeric simulations suggest that mis-specifying catchability could contribute to flawed stock assessments (Sampson, 1993; Chen and Paloheimo, 1998) and stock collapses (Walters and Maguire, 1996).

This study aims to examine the extent to which incorporating knowledge on annual catchability variations could contribute to enhancing the quality of stock assessments derived from XSA, which is now a usual procedure implemented by the ICES (International Council for the Exploration of the Sea) to assess fish stocks in the North-east Atlantic (e.g. ICES, 2000). A preliminary "Hybrid" analysis is carried out in order to identify the tuning fleets, which are prone to trends in catchability. XSA assessments are then carried out for a range of catchability trends, including values derived from the "Hybrid" method. The performance of these assessments is examined by means of a number of criteria based on XSA diagnostics. The above methodology is applied to the assessment of the North Sea stocks of cod, saithe, plaice and sole.

\section{MATERIAL AND METHODS}

\section{Stock assessments}

An exploratory analysis is carried out, for each tuning fleet individually, using the "Hybrid method" (Pope and Shepherd, 1985), so as to identify the tuning fleets that are subject to catchability trends. Stock assessments are then operated using the standard multi-fleet XSA (eXtended Standard Analysis) developed by Shepherd (1999). Information on the tuning fleets used in the XSA is given as annual series of landings at age and fishing effort. Fishing effort is traditionally expressed in time units fishing, possibly standardised with some measures of vessel attributes including horsepower, length or gross tonnage. The partial fishing mortality of species $s$ and recruited age group a, harvested by fleet $\mathrm{f}$, in year $\mathrm{y}$, may be related to catchability $\mathrm{q}$ and fishing effort $\mathrm{E}$, using Equation (1)

$$
F(s, f, y, a)=q(s, f, a,) E(f, y)
$$

We now make two assumptions. First, we assume that the catch data used as inputs to XSA stock assessments are correct. Second, we assume, consistently with some previous studies (Pascoe and Robinson, 1996; Millischer et al., 1999), that catchability is not constant over time, and has increased through fishing power development. Catchability trends are hereby described by an exponential model, similarly to the "Hybrid" method (Pope and Shepherd, 1985), but making the additional assumption that trends are kept equal across age ranges. Equation (1) may then be transformed into Equation (2)

$$
\mathrm{F}(\mathrm{s}, \mathrm{f}, \mathrm{y}, \mathrm{a})=\mathrm{q}(\mathrm{s}, \mathrm{f}, \mathrm{a},) e^{\alpha \cdot \ln (\mathrm{y}-\mathrm{T}+1)} \mathrm{E}(\mathrm{f}, \mathrm{y})
$$


where $\alpha, \mathrm{T}$ and $\mathrm{q}$ respectively represent the annual growth in catchability, the final year of the tuning period and the catchability in the final year of the tuning period. Fishing effort is then adjusted by the exponential term of Equation (2), for the tuning fleets for which a trend in catchability has been detected by the single-fleet "Hybrid" assessment method.

The above methodology is applied to the assessment of cod, saithe, sole and plaice in the North Sea. The main tuning parameters, i.e. seasonal adjustment parameters, time series taper, ages below which catchability is dependent on stock size, ages above which catchability is independent of age, F shrinkage, and minimal standard error of fleet estimates of population size (Shepherd, 1999) of the current assessment $(\alpha=0 \%)$, are reported in ICES (2000). These tuning parameters are kept unchanged in the assessments performed with adjusted fishing effort, so as to highlight the focus on the catchability trends analysis.

\section{Performance criteria}

Performances of assessments operated with adjusted and non-adjusted fishing effort are compared using a number of criteria:

1- Improved precision of the estimates of Logcatchability for each selected tuning fleet

2- Reduced trends in the annual trajectories of the Log-catchability residuals for each selected tuning fleet

3- Enhanced consistency of the retrospective patterns

Criterion 1 is investigated by examining the coefficient of variation CV relative to the Log-catchability estimates

$$
\mathrm{CV}(\mathrm{s}, \mathrm{f}, \mathrm{a},)=\frac{\sigma(\mathrm{s}, \mathrm{f}, \mathrm{a})}{\ln [\mathrm{q}(\mathrm{s}, \mathrm{f}, \mathrm{a})]}
$$

where $\ln [q(s, f, a)]$ is the estimated value of $\log$ catchability and $\sigma(\mathrm{s}, \mathrm{f}, \mathrm{a}$,$) is the standard deviation$ associated with this estimate. Low CV should correspond to good agreement between the tuning fleet data and the populations as estimated by the XSA transformation of the catch data. $\sigma$ could have been used as an alternative criterion to CV. However, $\sigma$ is generally -as in the present assessments- not independent of the mean log-catchability.

Criterion 2 is investigated by examining the firstorder auto-correlation ACR of the Log-catchability residuals $\varepsilon(\mathrm{s}, \mathrm{f}, \mathrm{y}, \mathrm{a})$
$\operatorname{ACR}(\mathrm{s}, \mathrm{f}, \mathrm{a})=,\frac{\operatorname{COV}(\varepsilon(\mathrm{s}, \mathrm{f}, \mathrm{y}-1, \mathrm{a}), \varepsilon(\mathrm{s}, \mathrm{f}, \mathrm{y}, \mathrm{a}))}{\operatorname{VAR}(\varepsilon(\mathrm{s}, \mathrm{f}, \mathrm{y}, \mathrm{a}))}$

where COV and VAR refer to the covariance and the variance functions respectively. Values of ACR close to 1 would characterise trends in the residuals time series. Values of ACR close to -1 would indicate that the residuals time series are oscillating around a stable mean, with a period of 2 years. Finally, values of ACR close to 0 would identify a purely random process. Low trends in residuals are hence associated with values of ACR included in the range $[-1,0]$.

Criterion 3 is investigated by examining the distance (retrospective index) between the annual trajectories relative to some variables of interest, derived from assessments performed in different years. The variables under examination are fishing mortality, SSB and recruitment. The retrospective index associated with each of these variables is calculated through a double summation. The first summation sums, over the years of assessment $\mathrm{i}=\mathrm{T}_{\mathrm{A}}$, ..., $\mathrm{T}-1$, the relative distance between a variable in year $\mathrm{y}$, as assessed in year i ( $>$ y) and that variable in year $y$, as evaluated in the last assessment performed in year $\mathrm{T}$. The scalar derived from the first summation is then summed over the data period $\left[\mathrm{T}_{0}\right.$, $\mathrm{T}$ ], resulting in a retrospective index. Should the different assessments be perfectly consistent, each retrospective index would equate 0 . The retrospective indices IF, IS and IR respectively associated with these distances are formulated as

$$
I F(s)=\sum_{y=T_{0}}^{T}\left[\sum_{i=\operatorname{Max}\left(y, T_{A}\right)}^{T-1}\left(\frac{\bar{F}(s, y, i)-\bar{F}(s, y, T)}{\bar{F}(s, y, T)}\right)^{2}\right]
$$

$$
\begin{aligned}
& \operatorname{IS}(\mathrm{s})=\sum_{\mathrm{y}=\mathrm{T}_{0}}^{\mathrm{T}}\left[\sum_{\mathrm{i}=\operatorname{Max}\left(\mathrm{y}, \mathrm{T}_{\mathrm{A}}\right)}^{\mathrm{T}-1}\left(\frac{\operatorname{SSB}(\mathrm{s}, \mathrm{y}, \mathrm{i})-\mathrm{SSB}(\mathrm{s}, \mathrm{y}, \mathrm{T})}{\operatorname{SSB}(\mathrm{s}, \mathrm{y}, \mathrm{T})}\right)^{2}\right] \\
& \operatorname{IR}(\mathrm{s})=\sum_{\mathrm{y}=\mathrm{T}_{0}}^{\mathrm{T}}\left[\sum_{\mathrm{i}=\operatorname{Max}\left(\mathrm{y}, \mathrm{T}_{\mathrm{A}}\right)}^{\mathrm{T}-1}\left(\frac{\mathrm{R}(\mathrm{s}, \mathrm{y}, \mathrm{i})-\mathrm{R}(\mathrm{s}, \mathrm{y}, \mathrm{T})}{\mathrm{R}(\mathrm{s}, \mathrm{y}, \mathrm{T})}\right)^{2}\right]
\end{aligned}
$$

where $\mathrm{T}_{0}$ and $\mathrm{T}_{\mathrm{A}}$ are respectively the first year of the retrospective period and the year of the first assessment, $\overline{\mathrm{F}}$ is the fishing mortality averaged over the reference fully recruited ages, and $\mathrm{R}$ is the recruitment. Table 1 summarises information on the parameters used to calculate the three retrospective indices. 
TABLE 1. - Parameters used to calculate the retrospective indices IF, IS and IR.

\begin{tabular}{lccc}
\hline & Cod & Plaice & Sole \\
\hline F age range & $2-8$ & $2-10$ & $2-8$ \\
$\mathrm{~T}_{0}$ & 1980 & 1980 & 1980 \\
$\mathrm{~T}_{\mathrm{A}}$ & 1996 & 1996 & 1996 \\
$\mathrm{~T}$ & 1998 & 1998 & 1998 \\
\hline
\end{tabular}

\section{RESULTS}

Table 2 shows the tuning fleets being prone to significant trends in catchability at age (slope higher than twice standard error), as derived from the "Hybrid" analysis. All the trends under consideration are positive and exceed 5\% per year, which is a high level. The fact that no negative trends are identified for any age groups suggest that the positive trends observed are due to an overall increase in fishing power in some age groups, and not a change in the selectivity of the fleets. The trend in catchability of both English and Scottish seiners harvesting
TABLE 2. - Significant annual trends in catchability at age (\%) in tuning fleets as derived from the "Hybrid" method (Pope and Shepherd, 1985).

\begin{tabular}{llrr}
\hline Species & Tuning fleet & Age & Trend \\
\hline \multirow{2}{*}{ Cod } & English otter-trawlers & 2 & $11 \%$ \\
& & 3 & $15 \%$ \\
& & 4 & $9 \%$ \\
& English seiners & 5 & $14 \%$ \\
Saithe & Scottish seiners & 5 & $8 \%$ \\
Plaice & English groundfish survey & 5 & $10 \%$ \\
& English beam-trawlers & 4 & $12 \%$ \\
& & 5 & $6 \%$ \\
& & 6 & $6 \%$ \\
& & 7 & $8 \%$ \\
& & 9 & $13 \%$ \\
Sole & Dutch beam-trawlers & 10 & $6 \%$ \\
& & 11 & $7 \%$ \\
& & 6 & $6 \%$ \\
& English beam-trawlers & 8 & $8 \%$ \\
& & 13 & $10 \%$ \\
& & 12 & $18 \%$ \\
& & & $15 \%$ \\
\hline
\end{tabular}

cod applies to the same age class. As a result, these tuning fleets have been aggregated for convenience into one tuning fleet, hereafter referred to as "UK

TABLE 3. - Summarised information on the tuning fleets, for which a trend in catchability was detected using the "Hybrid" method (Pope and Shepherd, 1985), as derived from a standard stock assessment with no adjustment on fishing effort (ICES, 2000). Tuning information includes the scaled weight of these fleets relative to the other tuning fleets used in the assessment, the CV associated with the Log-catchability estimates and the first-order autocorrelation of the Log-catchability residuals calculated over the tuning period.

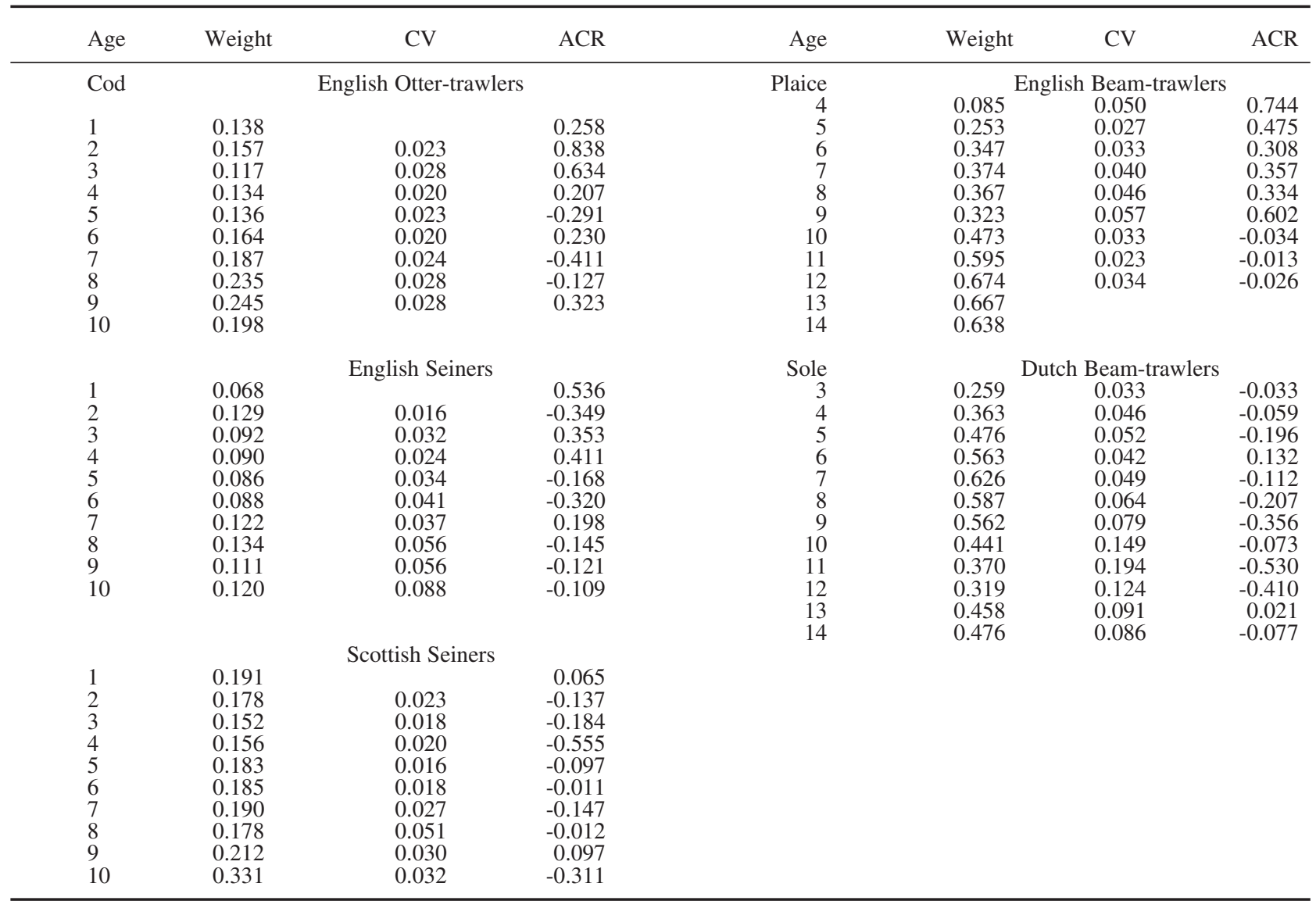


seiners". The high trend in catchability relative to the English beam-trawlers harvesting sole only applies to ages 11 and 12, which represent less than $5 \%$ of the catch in numbers. As a result, the English beam-trawlers harvesting sole are assumed to have constant catchability, for recruited ages, in subsequent XSA analyses. The only trend in catchability associated with saithe is detected for a survey. This unexpected outcome could be an artefact that would

a
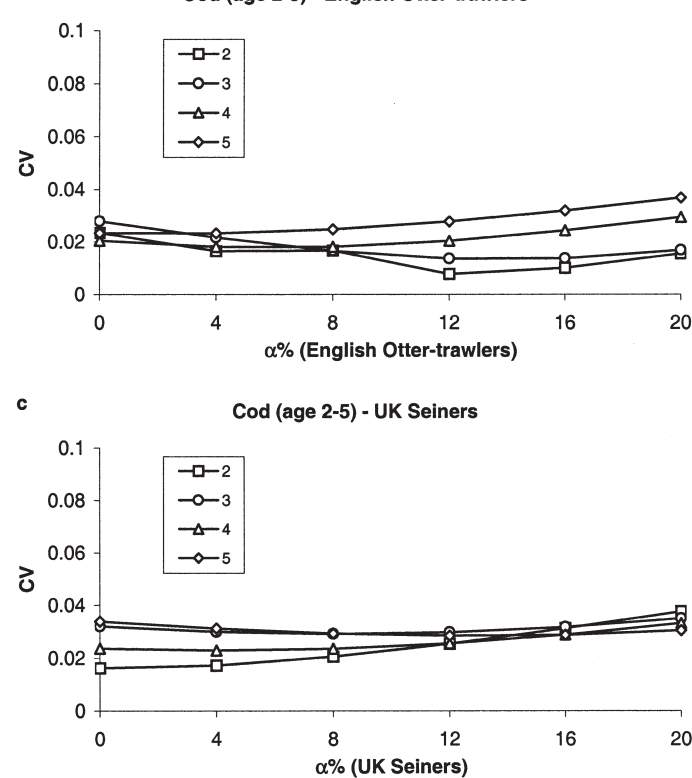

result from the English groundfish survey not being appropriate for estimating abundance indices relative to saithe. Overall, the tuning fleets harvesting saithe have constant catchability over time, and no subsequent analyses will be performed in relation to the saithe assessment.

Table 3 summarises information on the tuning fleets, for which a trend in catchability has been detected. The weight of the selected tuning fleets is
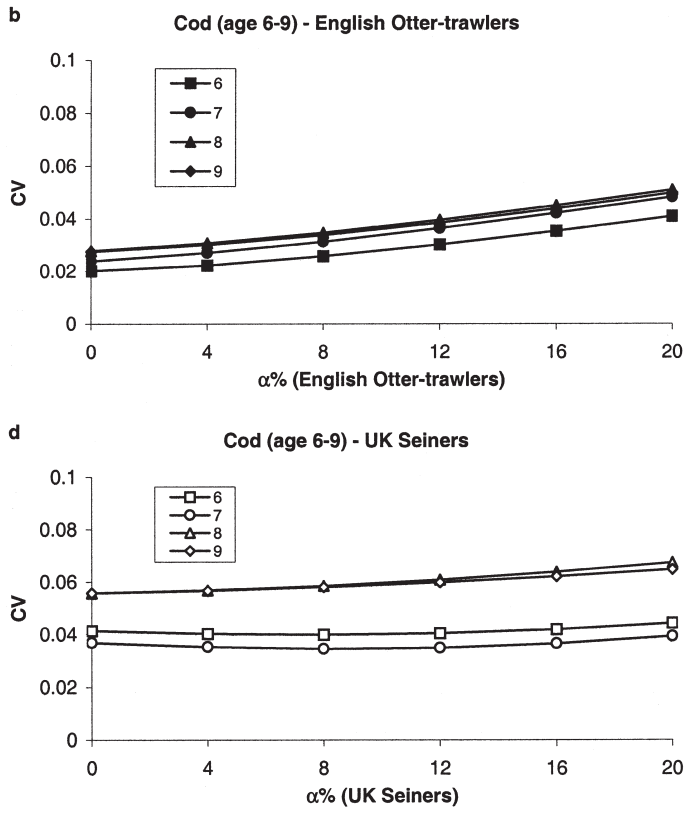

FIG. 1. - Coefficient of Variation (CV) relative to the estimation of Log-catchability versus annual increase in catchability, as derived from North Sea cod XSA assessment. The selected tuning fleets are the English otter-trawlers (age groups 2-5 (a) and 6-9 (b)) and the UK (English and Scottish) seiners (age groups 2-5 (c) and 6-9 (c)).
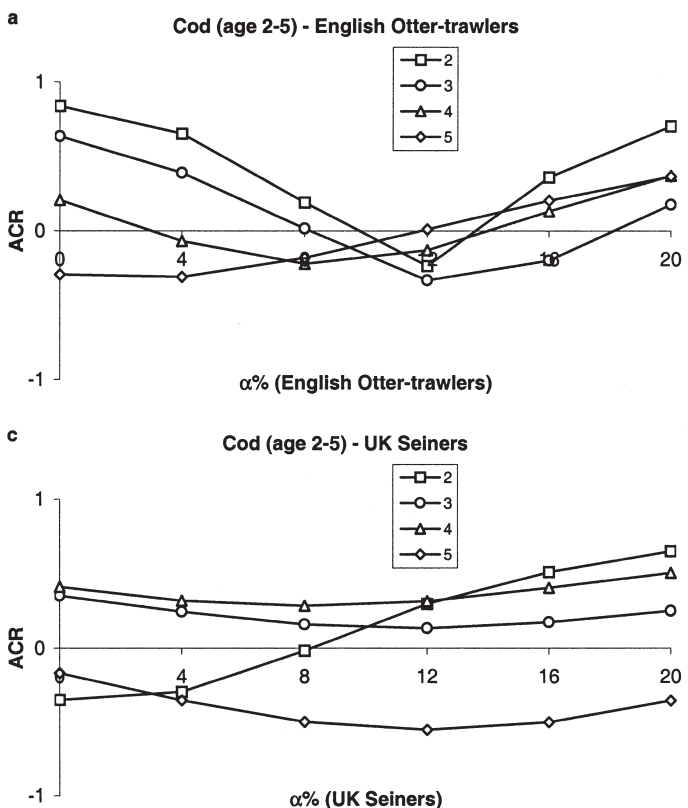

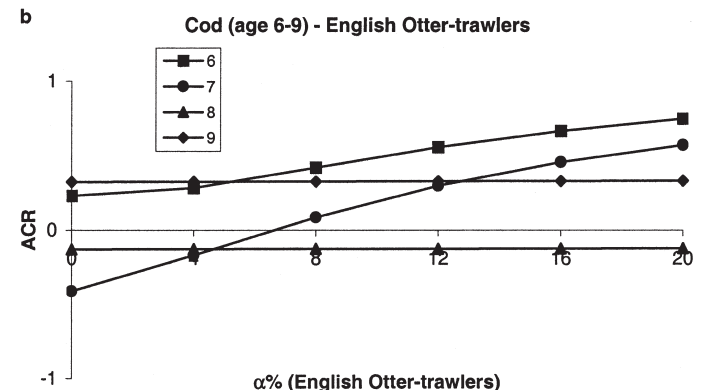

d

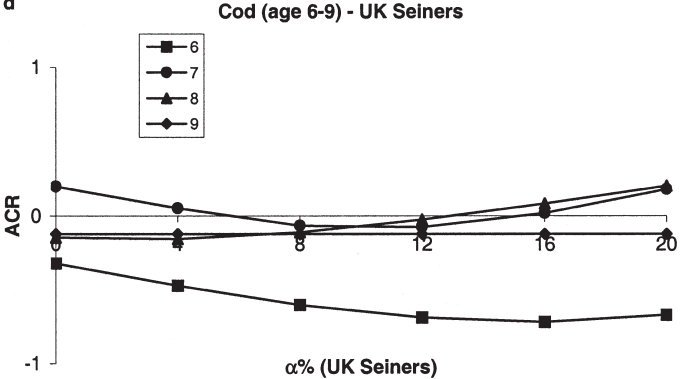

FIG. 2. - First-order auto-correlation (ACR) relative to the Log-catchability residuals versus annual increase in catchability, as derived from North Sea cod XSA assessment. The selected tuning fleets are the English otter-trawlers (age groups 2-5 (a) and 6-9 (b)) and the UK (English and Scottish) seiners (age groups 2-5 (c) and 6-9 (c)). 

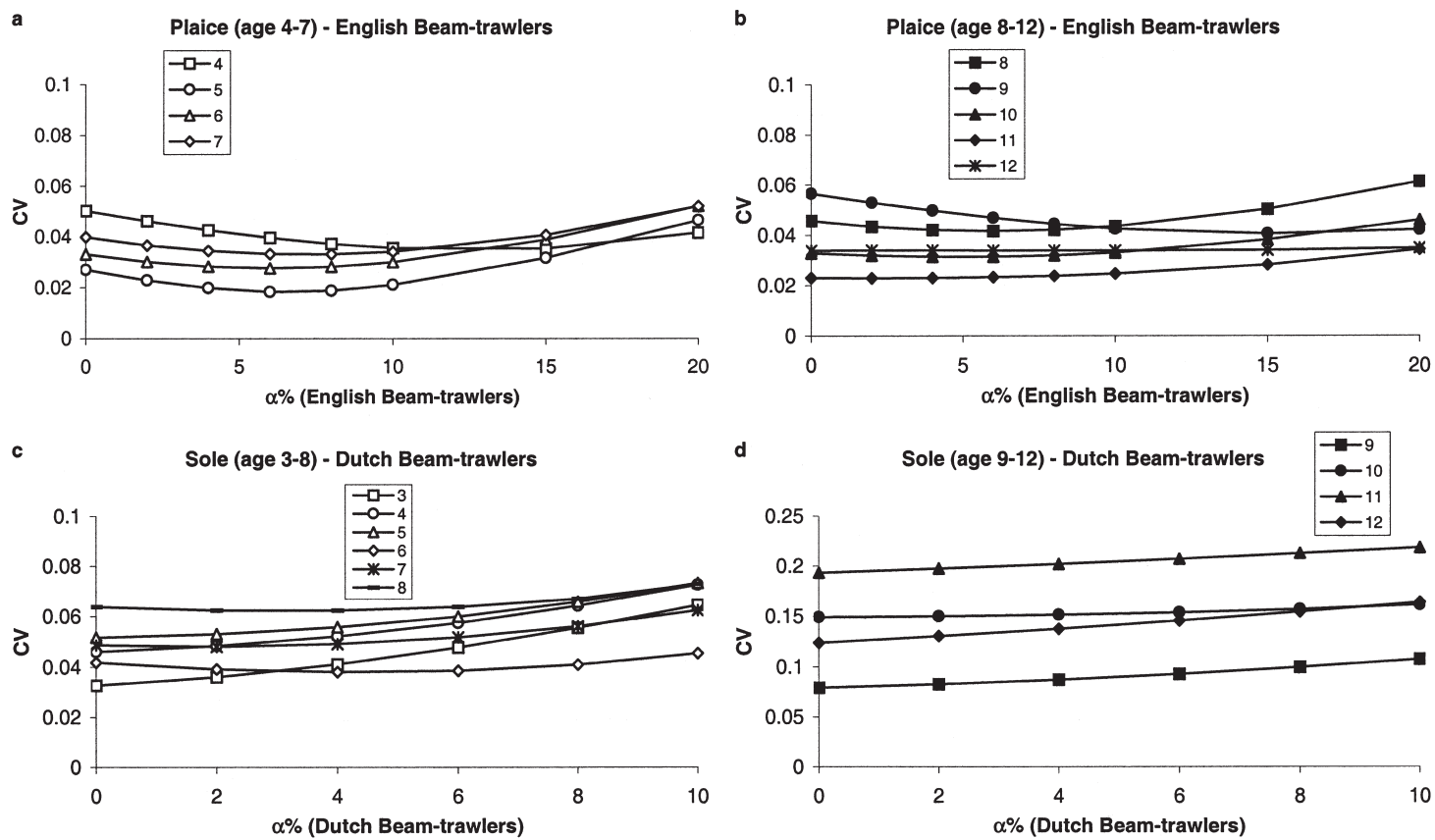

FIG. 3. - Coefficient of Variation (CV) relative to the estimation of Log-catchability versus annual increase in catchability, as derived from the North Sea plaice (age groups 4-7 (a) and 8-12 (b)) and sole (age groups 2-4 (c) and 5-9 (d)) XSA assessments. The selected tuning fleets are the English and Dutch beam-trawlers.

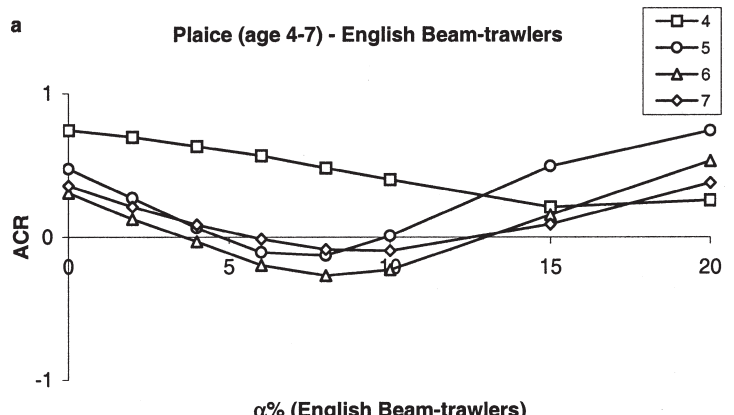

$\alpha \%$ (English Beam-trawlers)

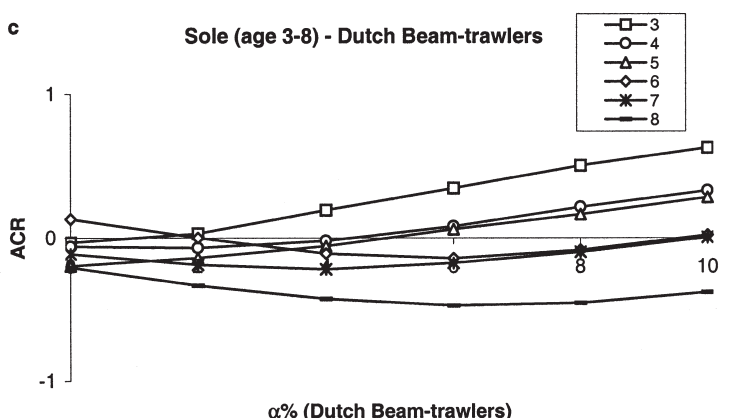

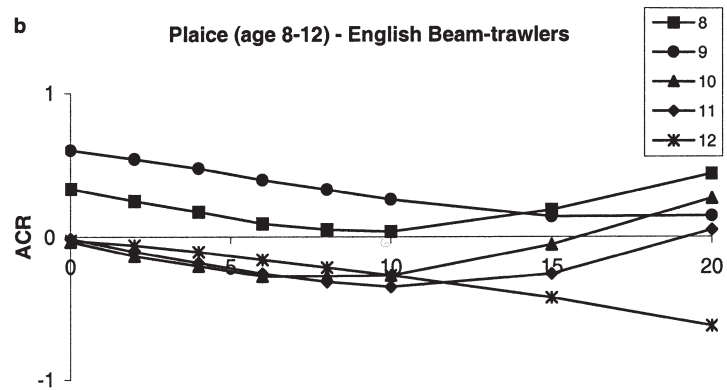

$\alpha \%$ (English Beam-trawlers)

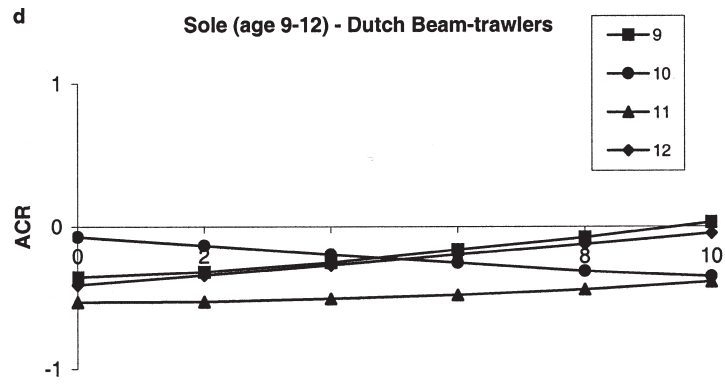

$\alpha \%$ (Dutch Beam-trawlers)

FIG. 4. - First-order auto-correlation (ACR) relative to the Log-catchability residuals versus annual increase in catchability, as derived from the North Sea plaice (age groups 4-7 (a) and 8-12 (b)) and sole (age groups 2-4 (c) and 5-9 (d)) XSA assessments. The selected tuning fleets are the English and Dutch beam-trawlers.

generally low (respectively high) in relation to young (respectively old) fish, and it is included in ranges $36-65 \%$ (cod), $9-67 \%$ (plaice) and 26-63\% (sole). The remaining weight is taken by the other tuning fleets for which no catchability trend has been detected.
Figures $1 \mathrm{a}, \mathrm{b}$ and $2 \mathrm{a}, \mathrm{b}$ show that adjusting fishing effort with $\alpha$ enhances the precision in the Log-catchability estimates and reduces trends in the Log-catchability residuals for English otter-trawlers harvesting cod, but only for young age groups 2-4. The minimal $\mathrm{CV}$ and 
TABLE 4. - Retrospective indices relative to the cod assessment, given as a function of catchability increase ( $\alpha \%)$ for UK (English and Scottish) Seiners and English otter-trawlers. The lowest values of IF, IS and IR are highlighted.

\begin{tabular}{|c|c|c|c|c|c|c|c|c|}
\hline & & & \multicolumn{6}{|c|}{ English Otter-trawlers $(\alpha \%)$} \\
\hline & & & 0 & 4 & 8 & 12 & 16 & 20 \\
\hline \multirow[t]{18}{*}{ UK Seiners $(\alpha \%)$} & \multirow[t]{6}{*}{ IF } & 0 & 0.09 & 0.09 & 0.09 & 0.08 & 0.08 & 0.08 \\
\hline & & 4 & 0.09 & 0.09 & 0.10 & 0.10 & 0.10 & 0.10 \\
\hline & & 8 & 0.10 & 0.11 & 0.13 & 0.13 & 0.14 & 0.13 \\
\hline & & 12 & 0.11 & 0.13 & 0.15 & 0.16 & 0.16 & 0.16 \\
\hline & & 16 & 0.12 & 0.14 & 0.16 & 0.17 & 0.17 & 0.17 \\
\hline & & 20 & 0.12 & 0.14 & 0.15 & 0.17 & 0.17 & 0.16 \\
\hline & \multirow[t]{6}{*}{ IS } & 0 & 0.09 & 0.07 & 0.05 & 0.05 & 0.05 & 0.05 \\
\hline & & 4 & 0.05 & 0.03 & 0.02 & 0.02 & 0.02 & 0.02 \\
\hline & & 8 & 0.04 & 0.02 & 0.02 & 0.02 & 0.01 & 0.01 \\
\hline & & 12 & 0.04 & 0.02 & 0.02 & 0.02 & 0.02 & 0.02 \\
\hline & & 16 & 0.04 & 0.03 & 0.02 & 0.02 & 0.02 & 0.02 \\
\hline & & 20 & 0.05 & 0.03 & 0.02 & 0.02 & 0.02 & 0.02 \\
\hline & \multirow[t]{6}{*}{ IR } & 0 & 0.21 & 0.19 & 0.17 & 0.16 & 0.16 & 0.17 \\
\hline & & 4 & 0.18 & 0.18 & 0.17 & 0.17 & 0.17 & 0.18 \\
\hline & & 8 & 0.19 & 0.19 & 0.19 & 0.19 & 0.20 & 0.20 \\
\hline & & 12 & 0.19 & 0.20 & 0.20 & 0.21 & 0.22 & 0.23 \\
\hline & & 16 & 0.19 & 0.20 & 0.20 & 0.21 & 0.23 & 0.24 \\
\hline & & 20 & 0.19 & 0.20 & 0.20 & 0.21 & 0.23 & 0.24 \\
\hline
\end{tabular}

ACR are both achieved at levels of $\alpha$ which roughly correspond to the values shown in Table 2. These results confirm that the fishing power of the English otter-trawl fishery has increased in relation to cod aged 2-4 years, which are the three most important age groups in terms of catch numbers at age (ICES, 2000). No dramatic improvements are brought about by adjusting the fishing effort of UK seiners harvesting cod (Figures $1 \mathrm{c}, \mathrm{d}$ and $2 \mathrm{c}, \mathrm{d}$ ).

Figures $3 \mathrm{a}, \mathrm{b}$ and $4 \mathrm{a}, \mathrm{b}$ show that increasing $\alpha$ both increases precision of Log-catchability estimates and decreases trends in Log-catchability residuals for age groups 4-9 of plaice exploited by English beamtrawlers. This result bears out the conclusions drawn from Table 2. Figures $3 c$,d indicate that increasing $\alpha$ contributes little to improving precision of the Logcatchability estimates relative to Dutch beamtrawlers harvesting sole. Increasing $\alpha$ reduces trends of the residuals relative to age group 6 for the same fishery (Figs. 4c,d). This result is partially in agreement with the outcomes of Table 2 .

Tables 4 and 5 show the retrospective indices relative to fishing mortality, SSB and recruitment of cod, plaice and sole, for the different assessments being examined. The lowest values of IF, IS and IR have been highlighted.

Figures 5, 6 and 7 contrast the retrospective patterns relative to fishing mortality, SSB and recruitment of cod, plaice and sole as derived from the standard assessment, with the retrospective patterns derived from the assessments providing the lowest IF, IS and IR (Tables 4 and 5).
Adjusting fishing effort overall does not affect the retrospective patterns in recruitment, for all stocks. IF and IS relative to cod are primarily affected by adjusting the fishing effort of the UK seiners. The assessment derived from combination (" $20 \% \mathrm{x}$ $8 \%$ ") provides the most consistent patterns in relation to SSB, but it does not really improve the retrospective pattern relative to fishing mortality. Adjusting the fishing effort of English beam-trawlers (respectively Dutch beam-trawlers) by applying a correction factor of $\alpha=10 \%$ enhances the overall assessment, by providing consistent retrospective patterns in relation to both fishing mortality and SSB of plaice (respectively sole).

Figure 8 represents the annual trajectories of fishing mortality (F), SSB and recruitment (R) derived from the North Sea cod, saithe, plaice and

TABLE 5. - Retrospective indices relative to the plaice and sole assessments, given as a function of catchability increase $(\alpha \%)$ for UK and Dutch beam-trawlers. The lowest values of IF, IS and IR are highlighted.

\begin{tabular}{|c|c|c|c|c|c|}
\hline Species & Tuning fleet & $\alpha \%$ & IF & IS & IR \\
\hline Plaice & English Beam-trawlers & $\begin{array}{r}0 \\
2 \\
4 \\
6 \\
8 \\
10\end{array}$ & $\begin{array}{l}0.17 \\
0.12 \\
0.09 \\
0.07 \\
0.05 \\
\mathbf{0 . 0 4}\end{array}$ & $\begin{array}{l}0.13 \\
0.10 \\
0.07 \\
0.06 \\
0.05 \\
\mathbf{0 . 0 4}\end{array}$ & $\begin{array}{l}0.73 \\
0.73 \\
0.73 \\
0.73 \\
0.73 \\
\mathbf{0 . 7 4}\end{array}$ \\
\hline Sole & Dutch Beam-trawlers & $\begin{array}{r}0 \\
2 \\
4 \\
6 \\
8 \\
10\end{array}$ & $\begin{array}{l}0.05 \\
0.03 \\
0.02 \\
0.02 \\
0.01 \\
\mathbf{0 . 0 1}\end{array}$ & $\begin{array}{l}0.04 \\
0.03 \\
0.02 \\
0.01 \\
0.01 \\
\mathbf{0 . 0 0}\end{array}$ & $\begin{array}{l}0.15 \\
0.14 \\
0.13 \\
0.12 \\
0.11 \\
\mathbf{0 . 1 1}\end{array}$ \\
\hline
\end{tabular}



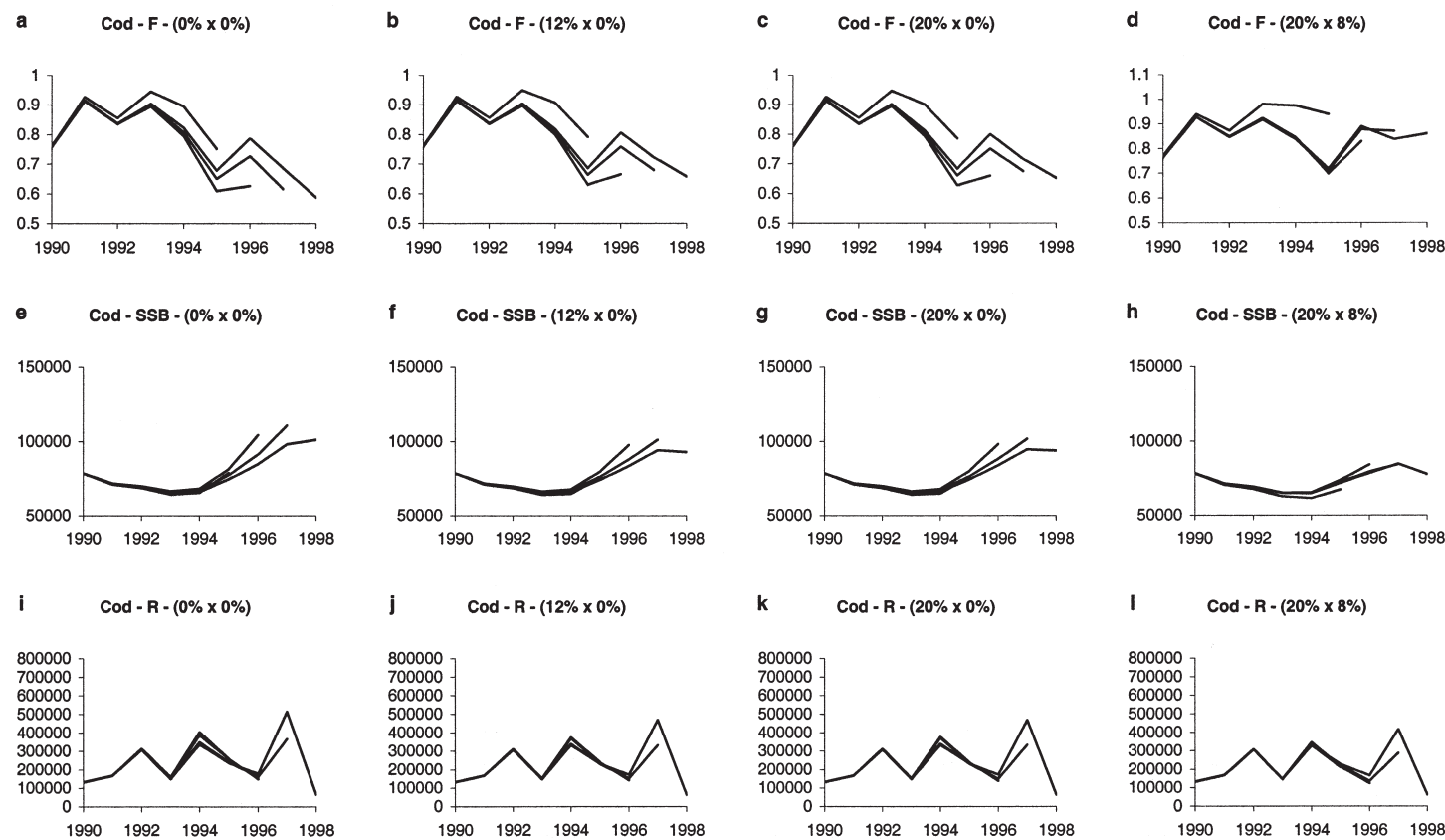

FIG. 5. - Retrospective patterns associated with the fishing mortality averaged over selected age groups (a-d), SSB (e-h) and recruitment (i1 ), as derived from the North Sea cod XSA assessments performed with selected values of " $\alpha \%$ (English otter-trawlers) x $\alpha \%$ (UK seiners)"
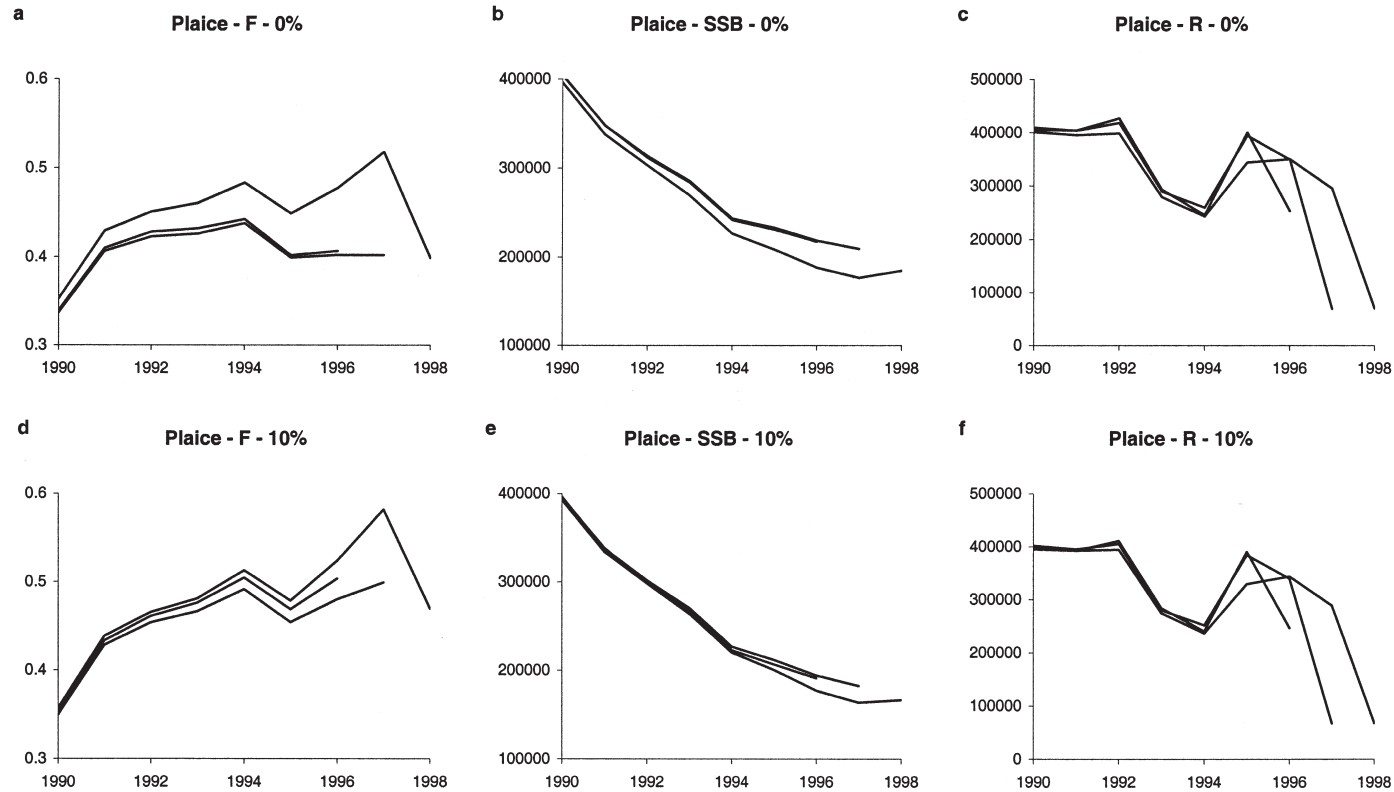

FIG. 6. - Retrospective patterns associated with the fishing mortality averaged over selected age groups (a-d), SSB (b-e) and recruitment (c-f), as derived from the North Sea plaice XSA assessments performed with selected values of " $\alpha \%$ (English beam-trawlers)".

sole assessments, performed with selected values of $\alpha$. The $\alpha$ values have been drawn from examination of Tables 4 and 5.

Ignoring annual increases in catchability overall results in an under-estimation of $\mathrm{F}$ and an over-estimation of both SSB and R. Thus, while the current cod and plaice assessments diagnose an increase of SSB between 1997 and 1998, assessments per- formed with $\alpha$ greater than $0 \%$ conclude that SSB has remained stable, at a different level (Fig. 8d). Likewise, while the current sole assessment diagnoses a reduction in F between 1997 and 1998, assessments performed with $\alpha$ greater than $0 \%$ conclude that $\mathrm{F}$ has increased over the same period (Fig. $8 c)$. Recruitment trajectories are not importantly modified by changes in $\alpha$ (Figs. 8g-i). 

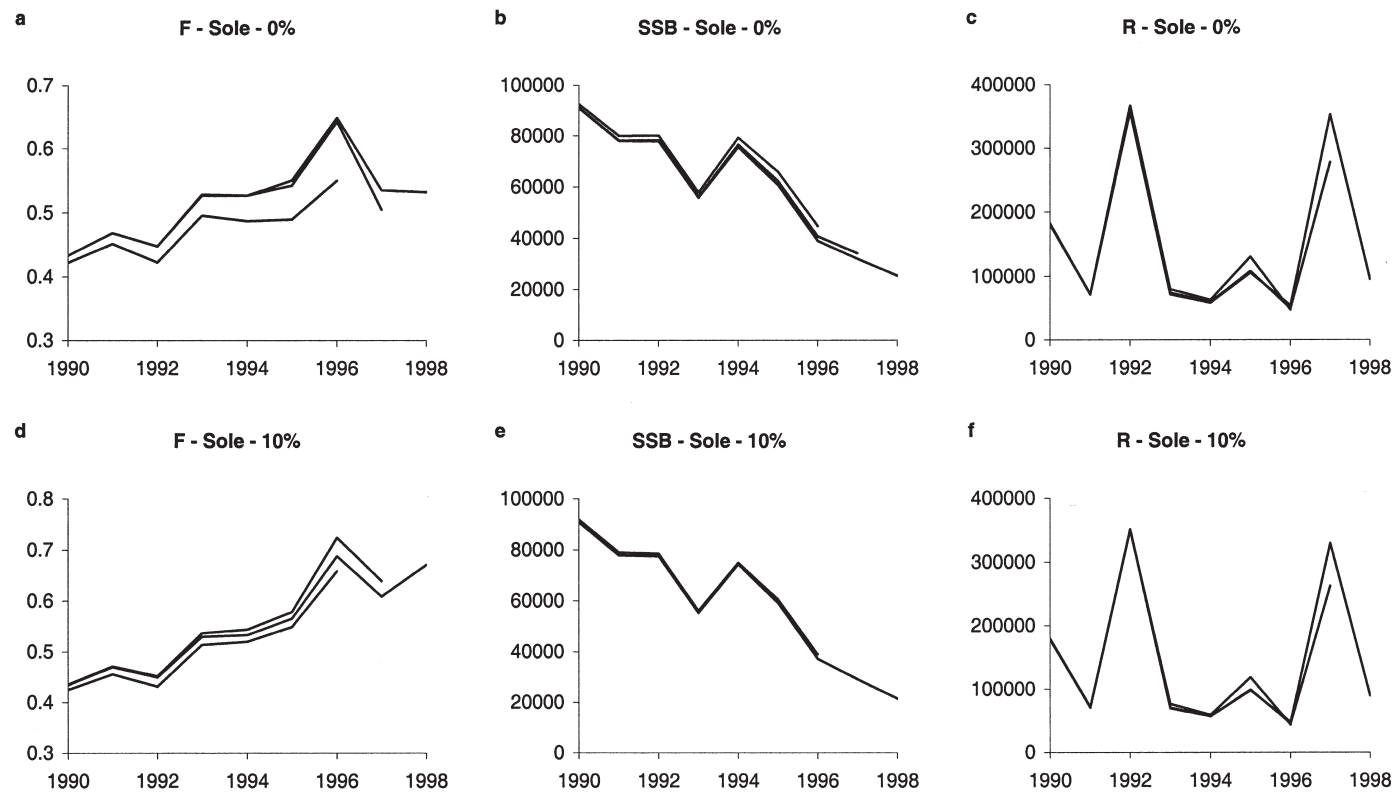

FIG. 7. - Retrospective patterns associated with the fishing mortality averaged over selected age groups (a-d), SSB (b-e) and recruitment (c-f), as derived from the North Sea sole XSA assessments performed with selected values of " $\alpha \%$ (Dutch beam-trawlers)".
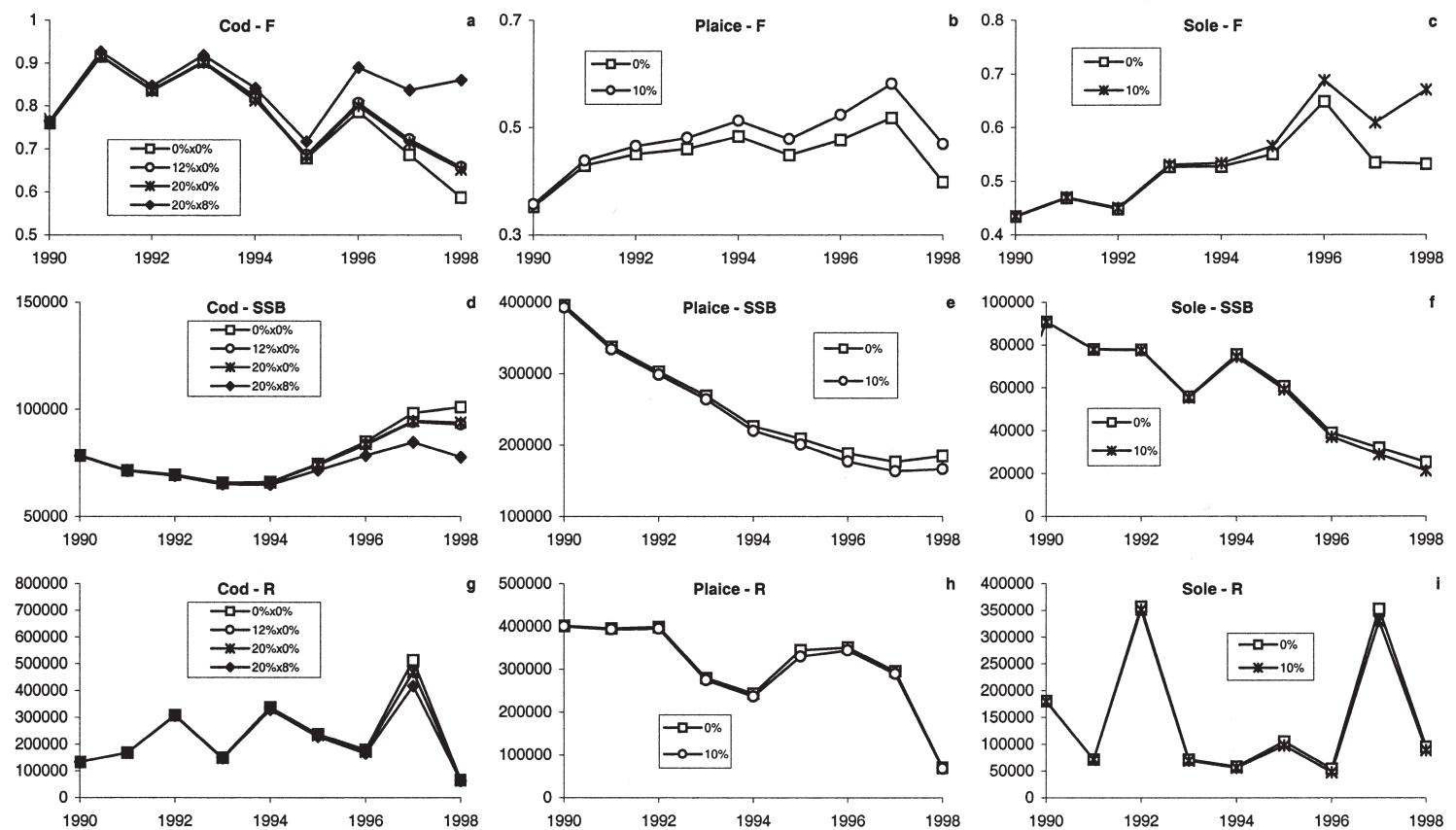

FIG. 8. - Annual trajectories of fishing mortality averaged over selected age groups (a-c), SSB (d-f) and recruitment (g-i), as derived from the North Sea cod (a, d, g), plaice (b, e, h) and sole (c, f, i) XSA assessments performed with selected values of $\alpha$. The tuning fleets of which fishing effort has been adjusted include the English otter-trawlers (cod), the UK (English and Scottish) seiners (cod), the Dutch and English beam-trawlers (plaice and sole).

\section{DISCUSSION}

The main conclusion of this study is that accounting for time variations in catchability would result in: (i) some improvement in the performances of traditional stock assessments; and (ii) new perceptions of the biomass and fishing mortality historical trends.
Adjusting the fishing effort of English beamtrawlers and Dutch beam-trawlers harvesting plaice and sole by the fishing power development estimated for these tuning fleets (about 10\%) would increase the precision of catchability estimates, reduce trends in Log-catchability residuals and make the retrospective patterns relative to fishing mortality and spawning biomass more consistent. 
By contrast with the standard assessment, assessments performed with adjusted fishing effort diagnose an increase in the fishing mortality of sole between 1997 and 1998 .

Adjusting the fishing effort of English ottertrawlers harvesting cod by accounting for a $12 \%$ annual trend in fishing power would increase the precision of catchability estimates and reduce trends in Log-catchability residuals. Despite limited effects on the retrospective indices, the assessments performed with adjusted fishing effort diagnose, by contrast with the standard assessment, that the spawning biomass of cod remains stable between 1997 and 1998. Results also suggest that adjusting the fishing effort of the UK seiners harvesting would not improve the assessment performance much.

There are limitations to the present approach, and these are debated below.

Catchability dynamics have here been modelled through a simple single-parameterised exponential regression of fishing power over time. In fact, the time dynamics of catchability could be more complex. First, while fishing power could increase over given periods through technical development (Pascoe and Robinson, 1996), it would be expected to reach some kind of technological plateau in the future, and it could even decrease over other periods through management constraints (Gillis et al., 1995) or competition between fishing vessels (Gillis and Peterman, 1998). Second, it was assumed here that deterministic time dynamics in catchability only occurred through changes in fishing power. However, non-random variations may also occur through other components of catchability such as selectivity (Fryer, 1991; Sampson, 1993) and vulnerability (Arreguin-Sanchez and Pitcher, 1999). A more complex catchability model would give a better fit than the single-parameterised exponential model used in this study, but at the expense of a decreased robustness, and particularly a higher sensitivity to parameter uncertainty. It would appear difficult to measure the optimal level of complexity required for modelling changes in catchability over time. This task however, is outside the scope of this study.

Another limitation of the approach being undertaken in this study lies in the assumptions inherent to the other XSA inputs and parameters. Thus, we have assumed that the catch rates data were correct. In fact, the quality of these data could well be adversely altered as a result of mis-reporting, which is thought to occur, particularly in the case of cod and plaice (ICES, 2000). In addition, the reliability of catch rates as stock abundance index could be questioned as fish and fishing vessels are often subject to spatial aggregations (ICES, 2000). Finally, natural mortality is assumed to be constant over time. If, as evidence suggest, natural mortality was prone to non-random variation over time (Rice and Gislason, 1996), ignoring such dynamics would annihilate some of the benefits brought about by accounting for catchability dynamics, particularly with regard to fishing mortality estimates.

Further research could be carried out in several directions. First, a more comprehensive model of catchability dynamics could be developed so as to standardise the fishing effort of the tuning fleets more accurately. The catchability model, possibly combined with another model describing some of the dynamics in natural mortality (e.g. ICES, 1997), could then, if successfully tested against existing data, be considered as an auxiliary module to be included in ICES assessment packages. Second, the present approach could be further expanded to examine how sensitive the outcomes of mediumterm projections and the definition of biological reference points are to uncertainty in catchability dynamics.

\section{ACKNOWLEDGEMENTS}

This work was funded by the European Union (DG XIV, study no. 98/027), while the assessment data used to perform the analyses were kindly supplied by ICES. Their support is gratefully acknowledged.

\section{REFERENCES}

Arreguin-Sánchez, F. - 1996. Catchability: a key parameter for fish stock assessment. Rev. Fish Biol. Fish., 6: 221-242.

Arreguin-Sánchez, F. and T.J. Pitcher. - 1999. Catchability estimates and their application to the red grouper (Epinephelus morio) fishery of the Campeche Bank, Mexico. Fish. Bull., 97: 746-757.

Atran, S.M., and J.G. Loesch. - 1995. An analysis of weekly fluctuations in catchability coefficients. Fish. Bull., 93: 562-567.

Chen, Y. and J.E. Paloheimo. - 1998. Can a more realistic model error structure improve the parameter estimation in modelling the dynamics of fish populations? Fish. Res., 38: 9-17.

Cook, R.M. and D.W. Armstrong. - 1985. Changes in the catchability of cod, haddock, and whiting associated with the Scottish seine-net fleet. J. Cons. Int. Explor. Mer, 42: 171-178.

Crecco, V. and W.J. Overholtz. - 1990. Causes of density-dependent catchability for Georges Bank haddock (Melanogrammus aeglefinus). Can. J. Fish. Aquat. Sci., 47: 385-394.

Deriso, R.B., T.J. Quinn II and P.R. Neal. - 1985. Catch-age analysis with auxiliary information. Can. J. Fish. Aquat. Sci., 42: 815-824.

Fournier, D. and C.P. Archibald. - 1982. A general theory for ana- 
lyzing catch at age data. Can. J. Fish. Aquat. Sci., 39: 11951207.

Fryer, R.J. - 1991. A model of between-haul variation in selectivity. ICES J. Mar. Sci., 48: 281-290.

Gascuel, D., A. Fonteneau and E. Foucher. - 1993. Analyse de l'évolution des puissances de pêche par l'analyse des cohortes: application aux senneurs exploitant l'albacore (Thunnus albacares) dans l'Atlantique Est. Aquat. Living Resour., 6: 1530.

Gillis, D.M. and R.M. Peterman. - 1998. Implications of interference among fishing vessels and the ideal free distribution to the interpretation of CPUE. Can. J. Fish. Aquat. Sci., 55: 37-46.

Gillis, D.M., R.M. Peterman and E.K. Pikitch. - 1995. Implications of trip regulations for high-grading: a model of the fishing behavior of fishermen. Can. J. Fish. Aquat. Sci., 52: 402-415.

Gillis, D.M., E.K. Pikitch and R.M. Peterman. - 1995. Dynamic discarding decisions: foraging theory for high-grading in a trawl fishery. Behav. Ecol., 6: 146-154.

ICES. - 1997. Study Group on Multi-species Model Implementation in the Baltic. ICES CM 1997, J:2.

ICES. - 2000. Report of the Working Group on the assessment of demersal stocks in the North Sea and Skagerrak, Copenhagen, Denmark, 11-20 October 1999. ICES CM 2000, ACFM:7: 598 p.

Megrey, B.A. - 1989. Review and comparison of age-structured stock assessment models from theoretical and applied points of view. Am. Fish. Soc. Symp., 6: 8-48.

Millischer, L., D. Gascuel and A. Biseau. - 1999. Estimation of the overall fishing power: A study of the dynamics and fishing strategies of Brittany's industrial fleets. Aquat. Living Resour., 12: 89-103.

Paloheimo, J.E. - 1980. Estimation of mortality rates in fish populations. Transactions Am. Fish. Soc., 109: 378-386.

Pascoe, S., and C. Robinson. - 1996. Measuring changes in technical efficiency over time using catch and stock information. Fish. Res., 28: 305-319.

Pope, J.G., and J.G. Shepherd. - 1985. A comparison of the performance of various methods for tuning VPAs using effort data. $J$. Cons. Int. Explor. Mer, 42: 129-151.

Rice, J. and H. Gislason. - 1996. Patterns of change in the size spectra of numbers and diversity of the North Sea fish assemblage, as reflected in surveys and models. ICES J. Mar. Sci., 53: 12141225.

Sampson, D.B. - 1993. The assumption of constant selectivity and the stock assessment for widow rockfish, Sebastes entomelas. Fish. Bull., 91: 676-689.

Shepherd, J.G. - 1999. Extended survivors analysis: an improved method for the analysis of catch-at-age data and abundance indices. ICES J. Mar. Sci., 56: 584-591.

Swain, D.P., G.A. Nielsen, A.F. Sinclair, and G.A. Chouinard 1994. Changes in catchability of Atlantic cod (Gadhus morhua) to an otter-trawl fishery and research survey in the southern Gulf of St Lawrence. ICES J. Mar. Sci., 51: 493-504.

Walters, C.J. and J.-J. Maguire. - 1996. Lessons for stock assessment from the northern cod collapse. Rev. Fish Biol. Fish., 6: 125-137. 
